\title{
A comparison between the benthic Nordic gillnet and whole water column gillnet for characterizing fish assemblages in the shallow Lake Balaton
}

\author{
András Specziár ${ }^{1 *}$, Tibor Erős ${ }^{1}$, Ágnes I. György ${ }^{1,2}$, István Tátrai ${ }^{1}$ and Péter Bíró ${ }^{1}$ \\ 1 Balaton Limnological Research Institute of the Hungarian Academy of Sciences, 8237 Tihany, Hungary \\ ${ }^{2}$ University of Pannonia, Department of Limnology, 8200 Veszprém, Hungary
}

Received 5 March 2009; Accepted 9 June 2009

\begin{abstract}
Performance of the prescribed gear of the European Standard (i.e. $1.5 \mathrm{~m}$ deep Nordic gillnet) was compared with gillnets deep enough to cover the whole water column (WWCG) for characterizing fish assemblages in a large and shallow lake (Lake Balaton, Hungary). Differences in species number, relative abundance and biomass, and length distribution of fish were examined in both inshore and offshore habitats of the lake. Nordic gillnet samples provided comparable information to that of WWCG for both species richness and abundance and biomass of benthic species. However, substantial differences were found between the two net types in the representation of pelagic fish species (i.e. bleak, razor fish and asp). Overall, the WWCG provided different information with more precise (less variable) data on fish assemblage structure than the Nordic gillnet. Results suggest that identification of neither horizontal nor vertical gradients in within lake fish assemblage structure can be guaranteed with the Nordic gillnet alone even in such shallow lakes, like Lake Balaton. It was concluded that benthic Nordic gillnet samples should be complemented with information on fish occurring in the upper water layers (i.e. pelagic species) even in very shallow lakes either by using pelagic or floating gillnets or by whole water column gillnetting.
\end{abstract}

Key words: Nordic gillnet / EN 14757:2005 / representative sampling / pelagic fish species / shallow lake

\section{Introduction}

Representative fish assemblage data are required for environmental quality assessment and management, studying specific trophic processes, and for large scale environmental gradient analyses. Presently, gillnetting is probably the most commonly used fishing method for accessing fish assemblages in standing freshwaters. In order to ensure the comparability of gillnet data in both space and time, standardized sampling protocols were developed (Hammar and Filipsson, 1985; Mortensen et al., 1990; Fjälling and Fürst, 1991; Appelberg et al., 1995; Appelberg, 2000). In Europe, this process has resulted in an operative standard (CEN, 2005), which is largely based on the original Swedish Standard for sampling fish with multimesh gillnets (Appelberg et al., 1995). The suggested protocol has already been adopted in many European countries, particularly to fill the requirements of the Water Framework Directive of the European Union (e.g. Mehner et al., 2005; Gassner et al., 2006; Kubečka and Prchalová, 2006).

\footnotetext{
*Corresponding author: speci@tres.blki.hu
}

Although important results have been achieved during the last few decades on how to improve the representativity and comparability of gillnet data, there are still many unresolved questions. For example, it has been emphasized that further research is needed to develop more accurate corrections for size selectivity (Prchalová et al., 2009) and more reliable methods for incorporating benthic and pelagic gillnet data to whole lake CPUE estimations (Lauridsen et al., 2008). One possible problem of the European Standard of gillnet sampling (CEN, 2005) can be that it is based largely upon the sampling of benthic fish assemblages, and some complementary sampling of pelagic fish assemblages is required only in lakes with a maximum depth of $>10 \mathrm{~m}$. However, it is well documented that pelagic (or non-benthic) fish species may also play a very important role in large, shallow lakes, and their diversity and density may change considerably both within and among lake habitats (Holmgren and Appelberg, 2000; Olin et al., 2002; Mehner et al., 2005; Jeppesen et al., 2006; Tátrai et al., 2008; Olin et al., 2009). For example, in Denmark sampling by the European Standard (CEN, 2005) was complemented with more intense random 
sampling of pelagic habitats for lakes deeper than $4.5 \mathrm{~m}$ (Lauridsen et al., 2005). As a result, Lauridsen et al. (2008) argued that the so called Danish method can give more reliable whole lake level fish community estimations compared to those suggested in the European Standard (CEN, 2005). Clearly, more studies are necessary for large and shallow lakes to reveal how much information is lost by the single application of the European Standard as compared with sampling methods which sample the whole water column.

The purpose of this study was to compare the performance of the prescribed gear of the European Standard (i.e. $1.5 \mathrm{~m}$ deep Nordic gillnet; CEN, 2005), with gillnets deep enough to cover the whole water column, in a large and shallow lake (Lake Balaton, Hungary). Specifically, we access the surplus information the use of the whole water column gillnets (WWCG) provide compared to the suggested European protocol of gillnet sampling. Differences in species number, relative abundance and biomass, and length distribution of fish are considered in both inshore and offshore habitats of the lake.

\section{Material and methods}

\section{Study area}

With its $593 \mathrm{~km}^{2}$ surface area, Lake Balaton is the largest shallow lake in Central Europe, situated at $46^{\circ} 42^{\prime}-$ $47^{\circ} 04^{\prime} \mathrm{N}, 17^{\circ} 15^{\prime}-18^{\circ} 10^{\prime} \mathrm{E}$ and $104.8 \mathrm{~m}$ above sea level. The lake is $78 \mathrm{~km}$ long, on average $7.6 \mathrm{~km}$ wide and $3.2 \mathrm{~m}$ deep. In $>99.9 \%$ of the lake area the water depth is $\leqslant 5 \mathrm{~m}$ and there is only a $c a$. 10 ha area at the end of the Tihany peninsula where the water depth ranges between 5 and $11 \mathrm{~m}$. Presently Lake Balaton is meso-eutrophic with mean annual chlorophyll-a concentrations of 3.6-18.7 mg.m ${ }^{-3}$ (Istvánovics et al., 2007). Forty-seven \% of the lake shore is covered by reed grass that corresponds to an 11071129 ha total covered area, but there are only sporadic patches of submerged macrophytes in the littoral zone. This slightly alkaline lake contains about $400 \mathrm{mg}^{-\mathrm{L}^{-1}}$ of $\mathrm{Ca}^{2+}$ and $\mathrm{Mg}^{2+}\left(\mathrm{HCO}_{3}^{-}\right)_{2}$, the $\mathrm{pH}$ varies within the range of 8.2-9.1 and the conductivity is 550-671 $\mu$ s.cm ${ }^{-1}$. A wind over $4 \mathrm{~m} . \mathrm{s}^{-1}$ velocity disturbs the loose sediment and disperses the solid particles in the whole water body. Although in exceptional cases (i.e. under ice cover) water transparency may reach $1.5-1.8 \mathrm{~m}$, in general the lake is turbid with Secchi depth varying between 0.2 and $0.8 \mathrm{~m}$. During this study the Secchi depth was $0.52 \pm 0.14 \mathrm{~m}$ (mean $\pm \mathrm{SD}$ ). Oxygen deficiency has never been registered in the lake and also concentrations of pollutants are low or insignificant.

The fish fauna of the lake consists of 30 permanent species of which common bream Abramis brama (L.), razor fish Pelecus cultratus (L.), bleak Alburnus alburnus (L.) and the introduced silver carp Hypophthalmichthys molitrix (Valenciennes) are the most abundant in biomass (Bíró, 1997; Specziár et al., 2000). Lake Balaton is one of the most intensively studied lakes in Europe, thus there are several reviews on its limnology (e.g. Herodek et al., 1988; Istvánovics et al., 2007) and fish fauna (e.g. Bíró, 1997; Specziár et al., 2000) which can serve as a source of further information on its biological and physical-chemical characteristics.

\section{Gears and sampling protocol}

The Nordic multimesh benthic gillnet (made by Nippon Verkko oy, Finland) is composed of 12 different mesh-sizes ranging from 5 to $55 \mathrm{~mm}$ (knot to knot) and it is $1.5 \mathrm{~m}$ deep. Order of the panels of different mesh-sizes is fixed as 43, 19.5, 6.25, 10, 55, 8, 12.5, 24, 15.5, 5, 35 and $29 \mathrm{~mm}$. Each mesh panel is $2.5 \mathrm{~m}$ long and mounted on a $30 \mathrm{~m}$ long buoyancy line (linear density in water 7 g. $\mathrm{m}^{-1}$ ) and a $33 \mathrm{~mm}$ long lead line (linear density in air 22 g.m ${ }^{-1}$ ). The hanging ratio is 0.5 for all mesh-sizes (for more detailed description of this net see CEN, 2005). The whole water column gillnet (WWCG) was the deeper version of the Nordic gillnet, except the missing $5 \mathrm{~mm}$ mesh-size panel (also made by Nippon Verkko oy, Finland). Three and $4.5 \mathrm{~m}$ deep WWCGs were used in order to secure the sampling of the whole water column in both inshore and offshore habitats. In the inshore area (1.6 to $2.8 \mathrm{~m}$ water depth) the $3 \mathrm{~m}$ deep WWCG, while in the offshore area (3.2 to $4.5 \mathrm{~m}$ water depth) the $4.5 \mathrm{~m}$ deep WWCG were used.

Between April 2006 and May 2007, altogether 26 trials (156 gillnet sets) were performed. Twelve trials were carried out in the inshore area at 50 to $200 \mathrm{~m}$ distance from the shore and 14 trials in the offshore area at least $1500 \mathrm{~m}$ from the nearest shoreline. In each trial three Nordic gillnets and three WWCGs were set linearly at the same water depth in randomized sequence and with one net length gap between them. All sampling sites had smooth bottom with constant water depth and were free of macrophytes and any other objects on the lake-bed.

Gillnets were set in the morning (after sunrise) for one to four hours sampling intervals based on our previous experience on expected CPUE values by sampling sites. Relatively short fishing times were set according to the high expected CPUE in productive and turbid Lake Balaton (Specziár et al., 2000; Specziár, 2001; Tátrai et al., 2008) and the recommended catch limit for the Nordic gillnet so as to avoid saturation of nets with fish (Olin et al., 2004; CEN, 2005). Fishing times were the same for all gillnet sets within a given trial.

\section{Data evaluation}

Catches of each net were handled separately. Since the WWCG did not include the $5 \mathrm{~mm}$ mesh-size panel, catches of this panel were also excluded from the Nordic gillnet samples. All fish were identified to species level, and standard length (SL) and mass measured in the laboratory. Gillnet catches were first standardized for one hour fishing time, and then converted to catch per unit effort (CPUE) 


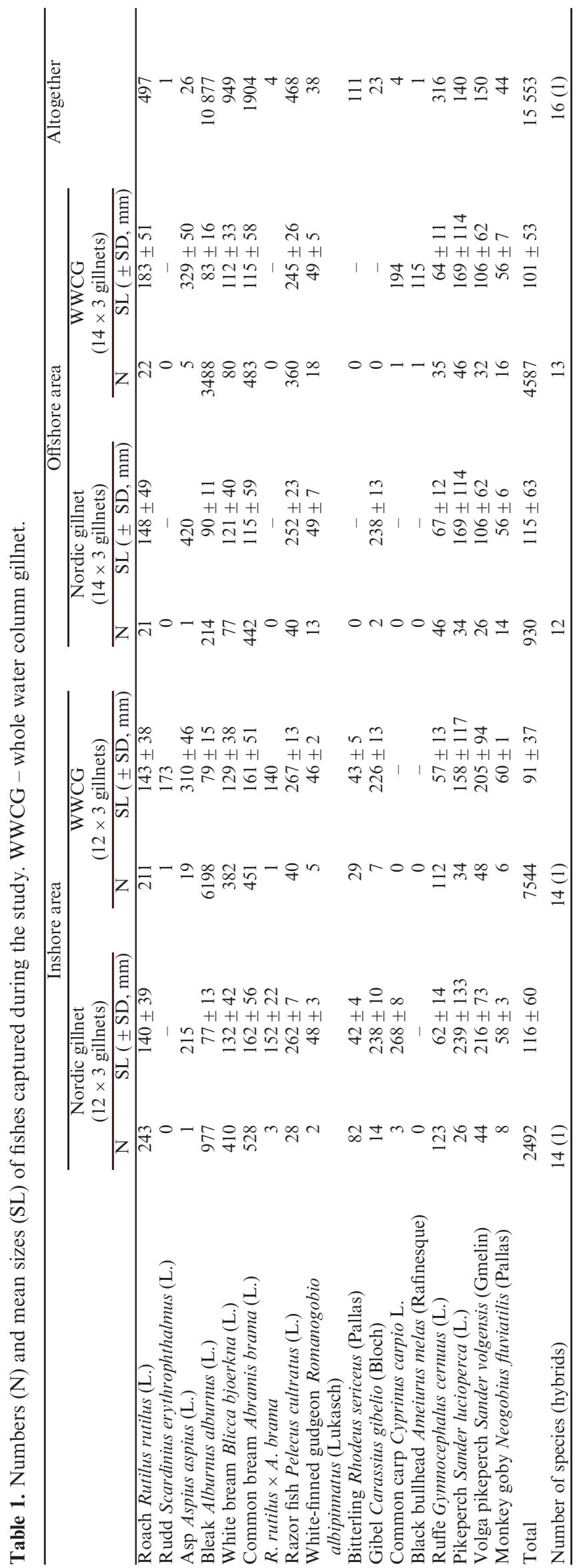

and expressed both in number (NPUE) and biomass (BPUE) of fish per one hour per standard net size. The standard net area was set to $41.25 \mathrm{~m}^{2}$ according to the area of the Nordic gillnet (without the $5 \mathrm{~mm}$ mesh-sized panel; $27.5 \mathrm{~m}$ long and $1.5 \mathrm{~m}$ deep). Standardization for the net area of the Nordic gillnet is common in fish assemblage studies (e.g. Olin and Malinen, 2003; Rask et al., 2003) and it is also suggested by the European Standard (CEN, 2005). In the WWCG the CPUE standardization was done according to the active net area which equalled the product of the net length and the water depth. It should be noted, however, that in case of species richness the fishing effort could not been standardized for gillnet area. Since the material and the mesh-size distribution of the studied nets were identical, size dependent gillnet selectivity was not considered in this study.

\section{Statistical analysis}

Rarefaction analyses were used to examine changes in the estimated number of species as a function of number of samples and number of individuals collected (Gotelli and Colwell, 2001). Analyses were performed with the EcoSim 7.72 software (Gotelli and Entsminger, 2008).

Principal component analysis (PCA) was run on square-root arcsin transformed relative abundance and biomass data to explore the distribution pattern of Nordic gillnet and WWCG samples. To obtain robust and readily interpretable results, PCA analyses were based on means of three parallel samples per gillnet type for each trial. Consequently, positions of 52 data points (two gillnet type, and 12 inshore and 14 offshore trials) were compared in the analyses. Since both water depth and duration of fishing varied among trials, effects of these factors on fish assemblage composition estimates were tested by correlating these factors with the principal component (PC) scores of fish assemblage composition data. These relationships were analysed with the Spearman rank correlation.

Differences between the number of species, and NPUE and BPUE values between the two net types (Nordic gillnet, WWCG) were compared with two-way repeated measures ANOVA. CPUE data were $\ln (x+1)$ transformed to approximate normality. Since CPUE data analyses included multiple statistical tests (45 ANOVAs were performed on both inshore and offshore CPUE data), the level of significance $(\mathrm{P})$ was adjusted using the Bonferroni correction to decrease the probability of type I error.

Precision of species number and CPUE estimates was quantified for the two gillnet types by determining the number of samples required for detecting $20 \%$ change of the mean value at $P<0.05$ (Krebs, 1989). Required sample sizes were determined with the iteration method based on the $t$-distribution.

Differences in fish length distribution data between gillnet types were analysed by using the chi-squared test for independent samples with the Bonferroni method for correction of significance level. 
Table 2. Mean NPUE and BPUE values of the Nordic gillnet and WWCG in the inshore and offshore areas of Lake Balaton. NPUE and BPUE values and species numbers between gears were compared with two way repeated measures ANOVA at $\mathrm{df}=11,1$ for the inshore and $\mathrm{df}=13,1$ for the offshore samples. $P$ values are given for between gear comparisons. *Denotes significant differences at $P<0.05$ following the Bonferroni correction. Significant between trial (sampling date) variations are indicated with underlining, also with Bonferroni correction and at $P<0.05$.

\begin{tabular}{|c|c|c|c|c|c|c|c|c|c|c|c|c|c|c|c|c|c|c|c|c|}
\hline & \multicolumn{10}{|c|}{ Abundance (a: ind. $\mathrm{h}^{-1}$. gillnet ${ }^{-1}$; b: ind. $\mathrm{h}^{-1} .41 .25 \mathrm{~m}^{-2}$ gillnet) } & \multicolumn{10}{|c|}{ Biomass (a: g.h ${ }^{-1}$.gillnet ${ }^{-1}$; b: g.h ${ }^{-1} .41 .25 \mathrm{~m}^{-2}$ gillnet) } \\
\hline & \multicolumn{5}{|c|}{ Inshore area } & \multicolumn{5}{|c|}{ Offshore area } & \multicolumn{5}{|c|}{ Inshore area } & \multicolumn{5}{|c|}{ Offshore area } \\
\hline & \multicolumn{2}{|c|}{ Nordic gillnet } & \multicolumn{3}{|c|}{ WWCG } & \multicolumn{2}{|c|}{ Nordic gillnet } & \multicolumn{3}{|c|}{ WWCG } & \multicolumn{2}{|c|}{ Nordic gillnet } & \multicolumn{3}{|c|}{ WWCG } & \multicolumn{2}{|c|}{ Nordic gillnet } & \multicolumn{3}{|c|}{ WWCG } \\
\hline & Mean & SD & $\overline{\text { Mean }}$ & SD & $\mathrm{P}$ & Mean & SD & $\overline{\text { Mean }}$ & SD & $\mathrm{P}$ & Mean & SD & $\overline{\text { Mean }}$ & SD & $\mathrm{P}$ & Mean & SD & $\overline{\text { Mean }}$ & SD & $\mathrm{P}$ \\
\hline & \multicolumn{20}{|c|}{ a) Data standardised for fishing time } \\
\hline Roach & 3.2 & 3.1 & 3.8 & 3.6 & 0.182 & 0.2 & 0.5 & 0.2 & 0.4 & 0.764 & 352 & 461 & 348 & 358 & $\underline{0.599}$ & 20 & 56 & 32 & 65 & 0.444 \\
\hline Asp & 0.0 & 0.1 & 0.3 & 0.5 & $<\overline{0.001} *$ & 0.0 & 0.1 & 0.0 & 0.1 & $\overline{0.112}$ & 4 & 17 & 107 & 228 & $<\overline{0.001} *$ & 10 & 67 & 22 & 64 & $\overline{0.108}$ \\
\hline Bleak & 10.7 & 16.2 & 96.1 & 93.3 & $<0.001 *$ & 1.6 & 4.1 & 41.7 & 32.7 & $<0.001^{*}$ & 85 & 123 & 649 & 591 & $<\overline{0.001 *}$ & 17 & 44 & 332 & 252 & $<0.001 *$ \\
\hline White bream & 3.8 & 2.8 & 4.9 & 3.9 & 0.073 & 0.7 & 1.7 & 0.6 & 1.3 & $\overline{0.777}$ & 341 & 274 & 389 & 336 & $\overline{0.951}$ & 40 & 81 & 27 & 60 & $\overline{0.856}$ \\
\hline Common bream & 5.0 & 4.3 & 5.7 & 4.4 & $\overline{0.270}$ & 3.8 & 4.4 & 3.9 & 2.9 & $\overline{0.099}$ & 615 & 483 & 736 & 686 & $\overline{0.786}$ & 223 & 216 & 250 & 200 & $\overline{0.248}$ \\
\hline Razor fish & 0.2 & 0.6 & 0.5 & 0.8 & $\overline{0.008}$ & 0.3 & 0.5 & 3.5 & 3.5 & $<\overline{0.001}^{*}$ & 39 & 88 & 88 & 140 & $\overline{0.112}$ & 50 & 71 & 497 & 485 & $<\overline{0.001} *$ \\
\hline Ruffe & 1.3 & 1.4 & 1.8 & 2.1 & $\overline{0.104}$ & 0.4 & 0.5 & 0.3 & 0.4 & $\overline{0.325}$ & 7 & 7 & 7 & 7 & $\overline{0.729}$ & 2 & 4 & 2 & 2 & $\underline{0.195}$ \\
\hline Pikeperch & 0.2 & 0.4 & 0.4 & 0.6 & $\overline{0.034}$ & 0.3 & 0.5 & 0.3 & 0.5 & $\overline{0.413}$ & 37 & 81 & 27 & 70 & $\overline{0.785}$ & 23 & 52 & 57 & 96 & $\overline{0.095}$ \\
\hline Volga $\mathrm{p}$ & 0.5 & 0.6 & 0.9 & 1.4 & $\overline{0.003}$ & 0.2 & 0.5 & 0.3 & 0.6 & $\overline{0.945}$ & 55 & 130 & 88 & 184 & 0.40 & 14 & 51 & 10 & 34 & $\overline{0.978}$ \\
\hline Other & 0.9 & 1.5 & 0.5 & 0.9 & $\overline{0.101}$ & 0.2 & 0.5 & 0.3 & 0.5 & $\overline{0.389}$ & 100 & 155 & 30 & 78 & $\overline{0.0}$ & 8 & 31 & 2 & 10 & $\overline{0.801}$ \\
\hline Total & 25.8 & 14.5 & 114.8 & 94.0 & $<\overline{0.001 *}$ & 7.8 & 8.2 & 51.0 & 32.9 & $<\overline{0.001^{*}}$ & 1635 & 844 & 2467 & 1070 & $<\underline{0.001 *}$ & 407 & 346 & 1229 & 743 & $<\underline{0.001 *}$ \\
\hline \multirow[t]{2}{*}{ Species number } & 6.6 & 1.5 & 6.9 & 1.7 & 0.295 & 4.3 & 1.8 & 5.4 & 1.6 & $<\underline{0.001^{*}}$ & & & & & & & & & & \\
\hline & \multicolumn{20}{|c|}{ b) Data standardised for fishing time and active net depth } \\
\hline Roach & 3.2 & 3.1 & 2.6 & 2.4 & 0.070 & 0.2 & 0.5 & 0.1 & 0.2 & 0.023 & 352 & 461 & 227 & 216 & 0.101 & 20 & 56 & 13 & 26 & 0.868 \\
\hline Asp & 0.0 & 0.1 & 0.2 & 0.3 & $<\overline{0.001} *$ & 0.0 & 0.1 & 0.0 & 0.1 & $\overline{0.409}$ & 4 & 17 & 70 & 144 & $<\overline{0.001} *$ & 10 & 67 & 10 & 28 & 0.148 \\
\hline Bleak & 10.7 & 16.2 & 72.1 & 82.9 & $<0.001 *$ & 1.6 & 4.1 & 15.6 & 11.8 & $<\underline{0.001^{*}}$ & 85 & 123 & 482 & 521 & $<\overline{0.001^{*}}$ & 17 & 44 & 126 & 93 & $<\underline{0.001^{*}}$ \\
\hline White bream & 3.8 & 2.8 & 3.1 & 2.4 & $\overline{0.020}$ & 0.7 & 1.7 & 0.3 & 0.6 & $<\overline{0.001^{*}}$ & 341 & 274 & 245 & 206 & 0.056 & 40 & 81 & 12 & 28 & 0.055 \\
\hline Common bream & 5.0 & 4.3 & 3.6 & 2.6 & $\overline{0.071}$ & 3.8 & 4.4 & 1.6 & 1.4 & $<\overline{0.001^{*}}$ & 615 & 483 & 456 & 399 & $\overline{0.249}$ & 223 & 216 & 102 & 89 & $<\overline{0.001} *$ \\
\hline Razor fish & 0.2 & 0.6 & 0.3 & 0.5 & $\overline{0.212}$ & 0.3 & 0.5 & 1.4 & 1.4 & $<\overline{0.001^{*}}$ & 39 & 88 & 51 & 79 & $\overline{0.231}$ & 50 & 71 & 198 & 189 & $<\overline{0.001^{*}}$ \\
\hline Ruffe & 1.3 & 1.4 & 1.1 & 1.2 & $\overline{0.580}$ & 0.4 & 0.5 & 0.1 & 0.2 & $<\overline{0.001^{*}}$ & 7 & 7 & 4 & 4 & $\overline{0.206}$ & 2 & 3 & 1 & 1 & $<\overline{0.001 *}$ \\
\hline Pikeperch & 0.2 & 0.4 & 0.3 & 0.3 & $\overline{0.470}$ & 0.3 & 0.5 & 0.1 & 0.3 & $\overline{0.387}$ & 37 & 81 & 17 & 43 & $\overline{0.504}$ & 23 & 52 & 23 & 41 & $\overline{0.283}$ \\
\hline Volga pikeperch & 0.5 & 0.6 & 0.7 & 1.2 & $\overline{0.253}$ & 0.2 & 0.5 & 0.1 & 0.3 & 0.010 & 55 & 130 & 53 & 111 & $\overline{0.982}$ & 14 & 51 & 5 & 16 & 0.421 \\
\hline Other & 0.9 & 1.5 & 0.3 & 0.5 & $<0.001 *$ & 0.2 & 0.5 & 0.0 & 0.1 & $<\underline{0.001^{*}}$ & 100 & 155 & 13 & 32 & $<\overline{0.001} *$ & 8 & 31 & 1 & 2 & $\overline{0.087}$ \\
\hline Total & 25.8 & 14.5 & 84.4 & 85.0 & $<0.001^{*}$ & 7.8 & 8.2 & 19.4 & 11.9 & $<\overline{0.001^{*}}$ & 1635 & 844 & 1624 & 675 & $\overline{0.609}$ & 407 & 346 & 490 & 301 & 0.042 \\
\hline
\end{tabular}



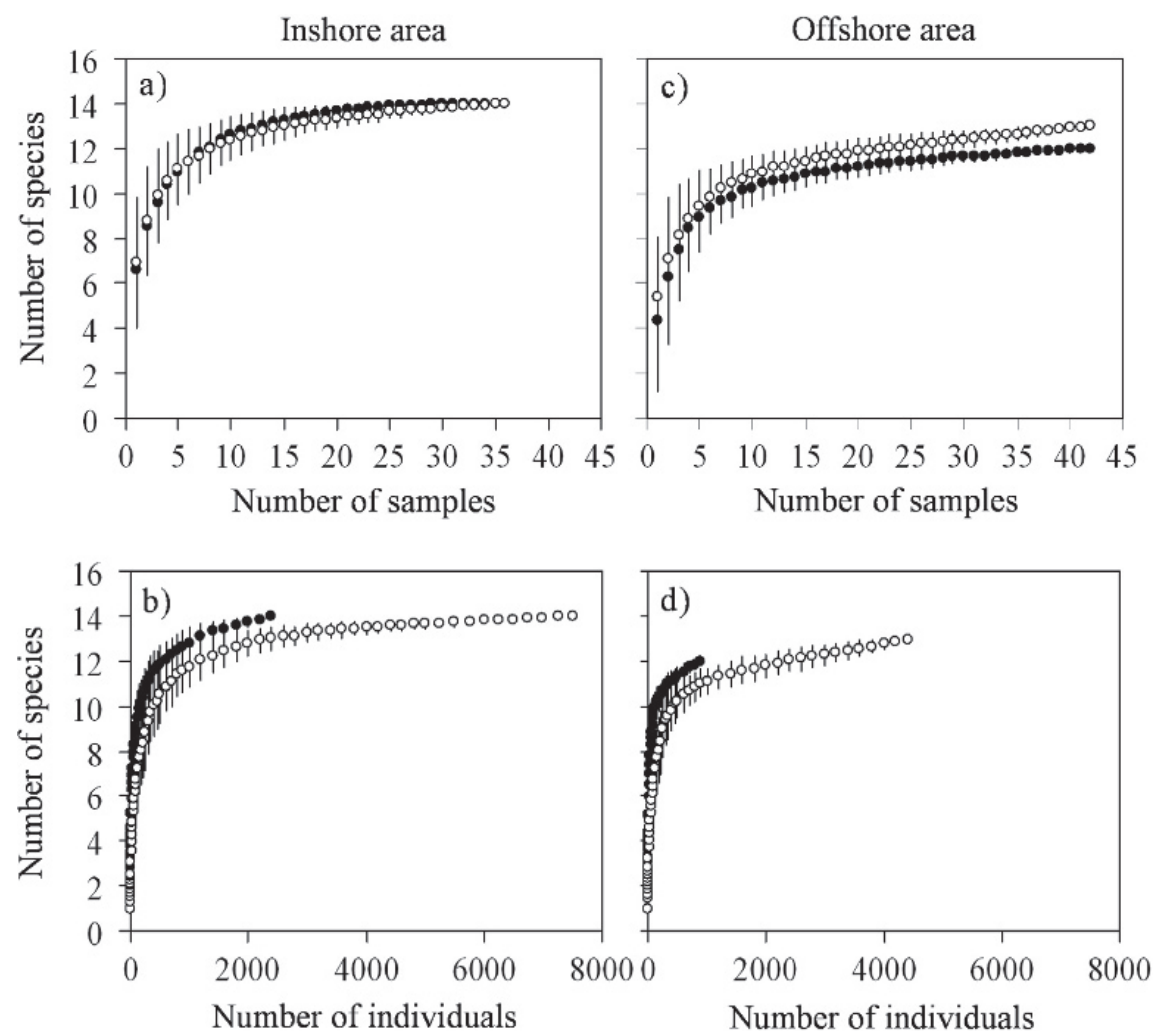

Fig. 1. Estimated number of species $( \pm \mathrm{SD})$ as a function of sample size $(n=36$ for inshore area and $n=42$ for offshore area) and number of individuals collected with the Nordic gillnet (filled circle, $N=2492$ for inshore area and $N=930$ for offshore area) and WWCG (open circle, $N=7544$ for inshore area and $N=4587$ for offshore area). a) Inshore area, estimated species number as a function of sample size; b) inshore area, estimated species number as a function of individuals collected; c) offshore area, estimated species number as a function of sample size; d) offshore area, estimated species number as a function of individuals collected.

Statistica 8.0 (StatSoft, Inc.) was used for all analyses except the species richness estimations.

\section{Results}

During the 26 fishing trials altogether 15553 individuals of 16 fish species and a hybrid were caught (Table 1). Most numerous species in the samples were bleak, common bream, white bream Blicca bjoerkna (L.), roach Rutilus rutilus (L.), razor fish and ruffe Gymnocephalus cernuus (L.).

\section{Species number}

Of the 16 fish species 14 were common for both gear types. Two species, rudd Scardinius erythrophthalmus (L.) and black bullhead Ameiurus melas (Rafinesque) were represented only in the WWCG samples, but each only with one individual. Compared to the Nordic gillnet, mean number of fish species caught by a single WWCG was higher in the offshore area but not in the inshore area (Table 2). The number of species caught changed similarly with sample size (number of gillnet sets) in both inshore and offshore areas for both gillnet types. However, the Nordic gillnet samples proved to be more species rich when the samples were standardized according to the number of individuals collected (Fig. 1).

\section{Catch composition}

According to the PCA gillnet samples separated by habitat and gear type (Fig. 2). For both numeric and biomass composition, $\mathrm{PCl}$ correlated positively with the increasing dominance of benthic species (i.e. common bream and ruffe) and negatively with the dominance of surface-oriented bleak. As such, PC1 separated samples mainly by gear type. PC2 correlated positively with the dominance of littoral species (i.e. roach and white bream) and negatively with the dominance of offshore razor fish. Consequently, PC2 separated samples mainly by habitat type. Scores of samples did not show any relationship with the duration of fishing along the determinative first three PC axes. PC1 scores of WWCG samples correlated with the water depth (Table 3). For the Nordic gillnet such relationship existed only along the less important $\mathrm{PC} 3$ axis.

\section{Catch per unit effort}

The WWCG caught much more pelagic fish (bleak, razor fish and asp Aspius aspius (L.)) per unit fishing time 

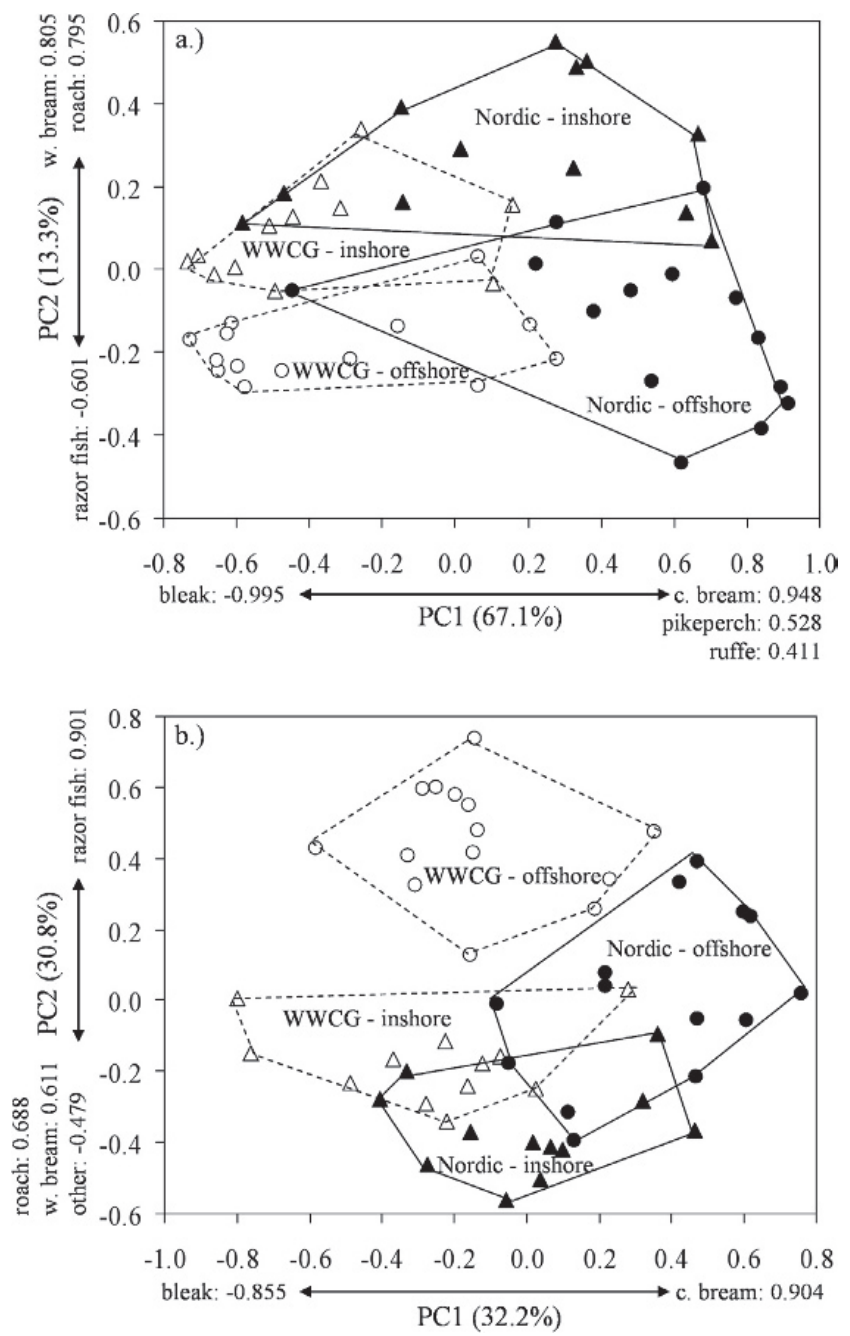

Fig. 2. Ordination by principal component analysis of Nordic gillnet (filled triangles represent inshore samples and filled circles represent offshore samples) and WWCG (open triangles represent inshore samples and open circles represent offshore samples) data based on square-root arcsin transformed relative numeric (a) and biomass (b) composition data, with convex hulls (continuous lines for Nordic gillnet samples and dotted lines for WWCG samples). Variance proportions represented by each PC are indicated together with the most important factor loadings (correlation).

than the Nordic gillnet (Table 2). Compared to the Nordic gillnet, the catchability of the WWCG in number was on average 8.9 times higher for bleak in the inshore area and 26.2 times higher in the offshore area, and 11.3 times higher for razor fish in the offshore area. In contrast, the two gillnet types caught similar amount of benthic fish per unit time. The total catch of the WWCG also markedly surpassed the total catch of the Nordic gillnet per unit time both in number and biomass.

When standardized for net area as well, the total NPUE and BPUE of the WWCG were still considerately higher in the inshore area, but the total CPUE equalled between the two gillnet types in the offshore area (Table 2).

\section{Required sample size}

The required sample size varied considerably depending on (1) the assemblage metric (i.e. species number, total abundance or abundance of a certain species), (2) the habitat and (3) the type of the gear (Table 4). The least number of samples (net sets) was needed to estimate changes in the species number. Depending on the net type 7-8 and 11-19 samples were needed to detect $20 \%$ changes in the species number in the inshore and offshore areas, respectively. In general, more samples were required for estimating CPUE in the offshore than in the inshore area, and for the Nordic gillnet than for the WWCG. Compared to the Nordic gillnet, variance of WWCG samples was lower for pelagic species (i.e. bleak, razor fish, asp). In contrast, no such differences were found for benthic species between net types.

\section{Size distribution}

Size distribution of fish in the total catches differed significantly between gear types in both inshore and offshore areas (chi-squared test for independent samples, $P<0.001)$. Compared to the WWCG, the Nordic gillnet caught less $\mathrm{SL}=50-110 \mathrm{~mm}$ fish (bleak) in the inshore, and less $\mathrm{SL}=50-110 \mathrm{~mm}$ (bleak) and $\mathrm{SL}=220-270 \mathrm{~mm}$ fish (razor fish) in the offshore area (Fig. 3).

In the inshore area, the size distribution of bleak, white bream and common bream, while in the offshore area the size distribution of bleak and pikeperch Sander lucioperca (L.) varied significantly between gear types (Table 5). However, most of the species-specific differences between the two gillnet types seemed to be random, except that in the WWCG samples the shares of smaller razor fish and bleak were higher compared to that in the Nordic gillnet samples (Fig. 3).

\section{Discussion}

The WWCG provided different information with more precise (less variable) data on fish assemblage structure than the Nordic gillnet in large and shallow Lake Balaton. The main differences between the two net types originated from the much higher representation of pelagic fish species in the WWCG samples.

WWCG samples were as or more species rich as Nordic gillnet samples. However, besides the two singleton species caught only by the WWCG, the Nordic gillnet could detect all the fish species which occurred in the whole water column samples. Consequently, if sampling intensity is high enough, the Nordic gillnet can substitute WWCG for monitoring changes in species richness. On the other hand, of the 30 fish species occurring in Lake Balaton (Bíró, 1997; Specziár et al., 2000) only 16 were detected during this study which indicates the significance of including larger mesh sizes into gillnet samplings (Tátrai et al., 2008) 
Table 3. Correlation (Spearman rank correlation, $\mathrm{R}_{\mathrm{s}}$ ) between the water depth and the scores of square-root arcsin transformed relative abundance and biomass data along the first three principal components (PC). ${ }^{*}$ Denotes significant correlation at $P<0.05$. WWCG - whole water column gillnet.

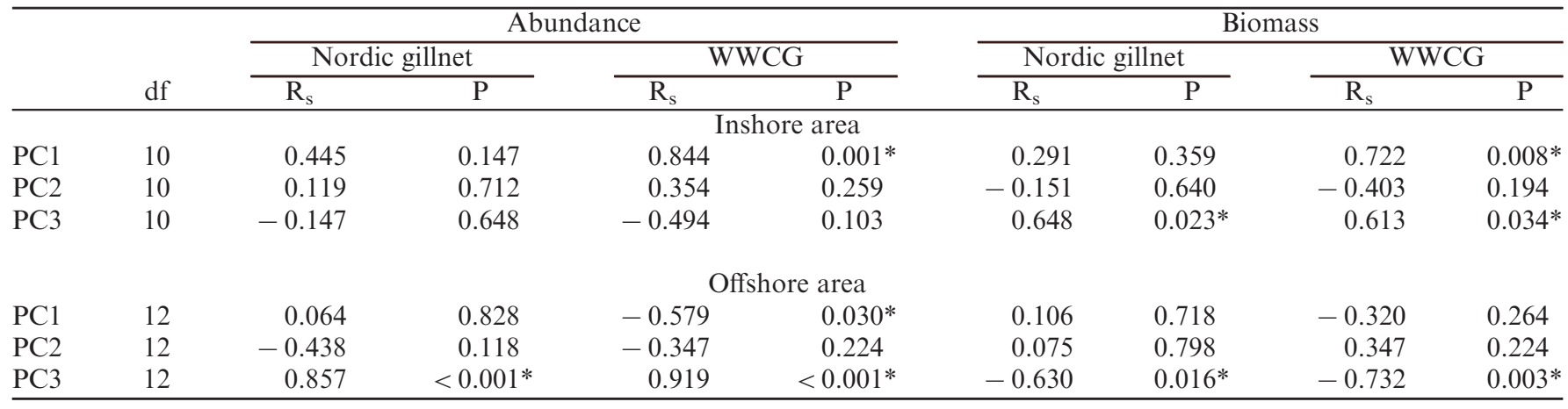

Table 4. Required sample sizes to reach $20 \%$ precision at $\alpha=5 \%$.

\begin{tabular}{|c|c|c|c|c|c|c|c|c|}
\hline & \multicolumn{4}{|c|}{ Abundance } & \multicolumn{4}{|c|}{ Biomass } \\
\hline & \multicolumn{2}{|c|}{ Inshore area } & \multicolumn{2}{|c|}{ Offshore area } & \multicolumn{2}{|c|}{ Inshore area } & \multicolumn{2}{|c|}{ Offshore area } \\
\hline & Nordic gillnet & WWCG & Nordic gillnet & WWCG & Nordic gillnet & WWCG & Nordic gillnet & WWCG \\
\hline Roach & 95 & 91 & 793 & 417 & 172 & 104 & 748 & 417 \\
\hline Asp & 1954 & 280 & 4200 & 788 & 1954 & 452 & 4200 & 872 \\
\hline Bleak & 227 & 94 & 662 & 62 & 209 & 83 & 678 & 58 \\
\hline White bream & 53 & 63 & 617 & 497 & 64 & 75 & 410 & 498 \\
\hline Common bream & 75 & 60 & 132 & 58 & 62 & 87 & 93 & 64 \\
\hline Razor fish & 565 & 256 & 206 & 100 & 516 & 253 & 203 & 95 \\
\hline Ruffe & 126 & 148 & 184 & 200 & 114 & 115 & 210 & 183 \\
\hline Pikeperch & 262 & 183 & 260 & 251 & 476 & 667 & 511 & 290 \\
\hline Volga pikeperch & 163 & 246 & 453 & 506 & 557 & 438 & 1298 & 1132 \\
\hline Other & 300 & 290 & 378 & 317 & 240 & 678 & 1740 & 1874 \\
\hline Total catch & 32 & 67 & 113 & 42 & 27 & 20 & 72 & 36 \\
\hline Species number ${ }^{1}$ & 7 & 8 & 19 & 11 & & & & \\
\hline
\end{tabular}

${ }^{1}$ Note in that case of species richness the fishing effort could not been standardized for gillnet area.

and using supplementary fishing methods in fish assemblage studies (Erös et al., 2009).

Present results suggest that the two gear types may give very similar results on species richness if the sampling intensity is high. However, when the sampling intensity is low, between gears comparison depends largely on the type of standardization. Between WWCG and Nordic gillnet, species richness was compared in relation to number of net sets used and number of individuals caught, but not for an unit gillnet area. The sampling area of the WWCG was considerably larger than that of the Nordic gillnet, and more over, it varied with the water depth. However, contrary to CPUE data, species richness estimates can not be adjusted posteriorly for gillnet area. Consequently, between gears differences revealed in the absolute and mean species richness data should be handled with caution, and also differences in the required sample size estimations regarding these measures may be biased.

This study prove that the $1.5 \mathrm{~m}$ deep Nordic gillnet is an effective tool for catching benthic fish species in shallow lakes, and that the catching efficiency of these fishes does not increase with the net depth above $1.5 \mathrm{~m}$. On the other hand, the difference between the catchability of the two net types was huge for pelagic fishes. Pelagic fish species, especially bleak and razor fish, play a very important role in the fish community of Lake Balaton (Bíró, 1997; Tátrai et al., 2008; Erős et al., 2009). In our study, bleak and razor fish comprised $29.9 \%$ of the total WWCG BPUE in the inshore and $67.4 \%$ in the offshore area. Further, while both gears proved that fish assemblage composition differs markedly between the inshore and offshore habitats, the two gillnetting methods gave largely different result on the significance of water depth in structuring the fish community. WWCG assemblage composition data (PC scores) indicated organization of fish assemblages along the depth gradient, especially in the inshore area. Nordic gillnet data did not reveal a similar pattern. The vertical segregation of fish assemblages in the water column is generally considered in the deep lakes research (e.g. Hansson, 1988; Peltonen et al., 1999; CEN, 2005; Helland et al., 2007). Such patterns are however rarely considered in the monitoring of shallow lakes (but see Olin and Malinen, 2003; Olin et al., 2009) and pelagic sampling is not required by the European Standard (CEN, 2005) for lakes shallower than $10 \mathrm{~m}$. However, our results suggest that identification of neither horizontal nor vertical gradients 


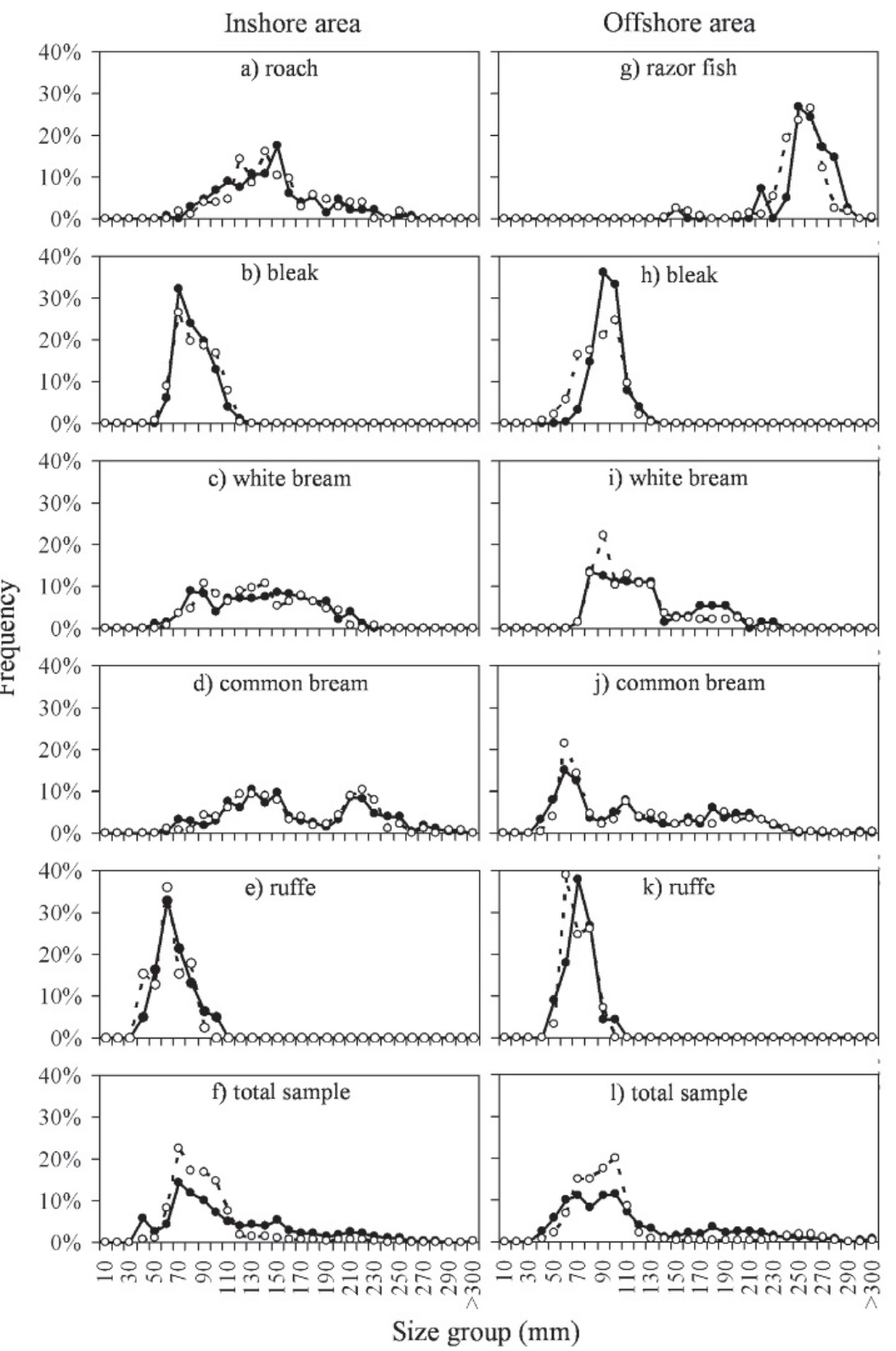

Fig. 3. Length distributions of the most abundant fish species and the total sample with the Nordic gillnet (filled circle) and WWCG (open circle) in the inshore (a-f) and offshore areas (g-1). Sample sizes and mean lengths of fish are given in Table 1.

in within lake fish assemblage structure can be guaranteed with the Nordic gillnet even in such shallow lakes, like Lake Balaton. Our study thus corroborates those of others (Mortensen et al., 1990; Lauridsen et al., 2005, 2008) which emphasised the importance of taking pelagic samples even for shallow lakes with a maximum depth of $4.5 \mathrm{~m}$.

Gillnetting is a passive sampling method whose performance is largely influenced by environmental and methodological factors. Since most fish species show diurnal activity rhythm and many of them group to shoals, timing and duration of gillnet sampling may influence gillnetting results (Olin et al., 2004, 2009; Vašek et al., 2009). In this study fishing was done in the morning and thus the density of fish which are active only at twilight or night (e.g. pikeperch) was possibly underestimated (Specziár, 2001; Olin et al., 2004; Vašek et al., 2009). In fact, the European Standard suggests overnight gillnetting (CEN, 2005), but dusk and night time gillnet sampling can also raise difficulties in productive shallow lakes with high fish density. It is well known that the catching efficiency of gillnets may substantially decline in time as the net saturates with fish. The rate at which catchability decreases is related to fish density (Hamley, 1975; Olin et al., 2004). In this study the fishing time was set to be relatively short and it varied between trials. The reason of this was to avoid the saturation of nets, especially those catching bleak. In the WWCG the upper 0.5-1 m part of the three most effective net panels $(8,10$ and $12.5 \mathrm{~mm}$ mesh-sizes, $c a .3 .25-7.5 \mathrm{~m}^{2}$ net area) caught on an average $649( \pm 591, \mathrm{SD}) \mathrm{g}$ bleak per hour in the 
Table 5. Results of the chi-squared statistics on differences between size distributions of fish in the Nordic gillnet and WWCG samples. Statistical analysis was performed only for relations where more than ten fish were caught per gillnet type. ${ }^{*}$ Denotes significant differences at $P<0.05$ following the Bonferroni correction.

\begin{tabular}{|c|c|c|c|c|c|c|}
\hline & \multicolumn{3}{|c|}{ Inshore area } & \multicolumn{3}{|c|}{ Offshore area } \\
\hline & $\chi^{2}$ & df & $\mathrm{P}$ & $\chi^{2}$ & df & $\mathrm{P}$ \\
\hline Roach & 34.2 & 16 & 0.005 & 2.7 & 2 & 0.259 \\
\hline Bleak & 55.9 & 6 & $<0.001 *$ & 76.7 & 7 & $<0.001^{*}$ \\
\hline White bream & 39.3 & 16 & $<0.001^{*}$ & 4.3 & 7 & 0.745 \\
\hline Common bream & 43.1 & 20 & $0.002 *$ & 22.0 & 18 & 0.232 \\
\hline Razor fish & 16.2 & 5 & 0.006 & 18.0 & 6 & 0.006 \\
\hline White-finned gudgeon & - & - & - & 0.1 & 2 & 0.951 \\
\hline Bitterling & 1.7 & 1 & 0.192 & - & - & - \\
\hline Ruffe & 6.9 & 5 & 0.228 & 4.8 & 4 & 0.308 \\
\hline Pikeperch & 7.6 & 3 & 0.055 & 14.1 & 3 & $0.003^{*}$ \\
\hline Volga pikeperch & 1.2 & 3 & 0.753 & 6.2 & 3 & 0.102 \\
\hline Monkey goby & - & - & - & 2.5 & 3 & 0.475 \\
\hline Total sample & 1389.8 & 27 & $<0.001^{*}$ & 521.7 & 28 & $<0.001 *$ \\
\hline
\end{tabular}

inshore and $332( \pm 252) \mathrm{g}$ bleak per hour in the offshore areas. Similarly short fishing time was applied by Olin et al. (2009) in Lake Hiidenvesi in southern Finland to avoid saturation of nets with fish. On the other hand, it is also suggested that when the fishing time is too short, the catch composition may be effected by differences in the activity patterns of fish (Specziár, 2001; Jacobsen et al., 2004; Olin et al., 2004; Vašek et al., 2009). Therefore, finding the optimal fishing time would be another important research topic for the scientifically sound monitoring of fish assemblages with gillnets in productive shallow lakes where overnight fishing seems to be irrational. Nevertheless, in this study there was not any significant relationship between the relative assemblage composition and the duration of fishing.

According to the standard use of gillnets (Hubert, 1996), nets should be fixed stretched to ensure the nominal stretching of meshes. In this study the WWCG was always deeper than the water depth and thus this criterion probably was not always met (e.g. when there was not any slight current in the sampling site). It is supposed that under such circumstances gillnets may work differently. In general, loosely hung nets tangle more fish in a wider size range, but net hanging has little effect on catches of fish that are usually caught wedged or gilled like most cyprinids (Hamley, 1975; and literature cited there). In the present study catches were dominated by cyprinid fishes which were not found tangled. In contrary, two percids, pikeperch and Volga pikeperch Sander volgensis (Gmelin) were sometimes tangled in both gillnet types. Based on observation in two reservoirs in the Czech Republic, Prchalová et al. (2008) also found that cyprinids are much more rarely tangled in gillnets than percids. Nevertheless, since the Nordic gillnet and the WWCG gave very similar estimates on benthic fish species, it can be supposed that this bias should be small compared to that when the upper water layers are excluded from the samplings.

To conclude we found that Nordic gillnet samples provide comparable information to that of WWCG for both species richness estimation and for abundance and biomass of benthic species. However, our study underpins that Nordic gillnet samples should be complemented with information on fish occurring in the upper water layers (i.e. pelagic species) even in very shallow lakes. Such information generally can be obtained from pelagic or floating gillnetting which method should thus be universalized in shallow habitats too. We also suggest that in situations when the working depth of the benthic and pelagic nets could not be separated clearly the use of the WWCG as a supplementary gear could be a good alternative choice. However, the performance of gillnets when they are not stretched correctly is still uncertain. This problem should get more attention in the future, particularly because at $<1.5 \mathrm{~m}$ water depth the Nordic gillnet itself suffers from slackness (e.g. Sutela et al., 2008).

Acknowledgements. We thank Géza Dobos for his help in the field and Beáta Maroskövi for her help in the laboratory work. This study was partially supported by the Hungarian Scientific Research Fund (OTKA No. T046222).

\section{References}

Appelberg M. (ed.), 2000. Swedish standard methods for sampling freshwater fish with multi-mesh gillnets. Fiskeriverket Information, 1, 32 p.

Appelberg M., Berger H.M., Hesthagen T., Kleiven E., Kurkilahti M., Raitaniemi J. and Rask M., 1995. Development and intercalibration of methods of Nordic freshwater fish monitoring. Water Air Soil Pollut., 85, 883-888.

Bíró P., 1997. Temporal variation in Lake Balaton and its fish populations. Ecol. Freshw. Fish, 6, 196-216.

CEN (European Committee for Standardization), 2005. Water quality - Sampling of fish with multi-mesh gillnets (14757: 2005), Brussels, 27 p.

Erős T., Specziár A. and Bíró P., 2009. Assessing fish assemblages in the littoral zone of a large shallow lake - a 
comparison between gillnetting and electric fishing. Fish. Res., 96, 70-76.

Fjälling A. and Fürst M., 1991. Preliminary manual for test-fishing in Zambian reservoirs. Fish. Dev. Series, 53, 27-44.

Gassner H., Zick D., Bruschek G., Mayrhofer K. and Frey I., 2006. Metodik - Handbuch. In: Fischbestandsaufnahme und Bewertung des okologischen Zustandes der naturlichen und kunstlichen Seen Osterreichs ( $>50$ ha) gemass EUWasserrahmenrichtlinie - Bundesamt fur Wasserwirtschaft, Institute fur Gewasserokologie, Fischereibiologie und Seenkunde, Mondsee, $27 \mathrm{p}$.

Gotelli N.J. and Colwell R.K., 2001. Quantifying biodiversity: procedures and pitfalls in the measurement and comparison of species richness. Ecol. Lett., 4, 379-391.

Gotelli N.J. and Entsminger G.L., 2008. EcoSim: Null Models Software for Ecology, Version 7, Acquired Intelligence Inc. \& Kesey-Bear, Jericho, available at http://www. garyentsminger.com/ecosim/ecosim.htm.

Hamley J.M., 1975. Review of gillnet selectivity. J. Fish. Res. Board Can., 32, 1943-1969.

Hammar J. and Filipsson O., 1985. Ecological testfishing with the Lundgren gillnets of multiple mesh size: The Drottningholm technique modified for Newfoundland Artic char populations. Rep. Inst. Freshw. Res. Drottningholm, 62, $12-35$.

Hansson S., 1988. A simple vertical gill net system for variable current conditions. Hydrobiologia, 160, 107-110.

Helland I.P., Freyhof J., Kasprzak P. and Mehner T., 2007. Temperature sensitivity of vertical distributions of zooplankton and planktivorous fish in stratified lake. Oecologia, 151, 322-330.

Herodek S., Laczkó L. and Virág Á., 1988. Lake Balaton: research and management, Nexus, Budapest, 110 p.

Holmgren K. and Appelberg M., 2000. Size structure of benthic freshwater fish communities in relation to environmental gradients. J. Fish Biol., 57, 1312-1330.

Hubert W.A., 1996. Passive capture techniques. In: Murphy B.R., Willis D.W. (eds.), Fisheries techniques, 2nd edition, American Fisheries Society, Bethesda, Maryland, 157-181.

Istvánovics V., Clement A., Somlyódy L., Specziár A., Tóth L.G. and Padisák J., 2007. Updating water quality targets for shallow Lake Balaton (Hungary), recovering from eutrophication. Hydrobiologia, 581, 305-318.

Jacobsen L., Berg S., Jepsen N. and Skov C., 2004. Does roach behaviour differ between shallow lakes of different environmental state? J. Fish Biol., 65, 135-147.

Jeppesen E., Pekcam-Hekim Z., Lauridsen T., Søndergaard M. and Jensen J.P., 2006. Habitat distribution of fish in late summer: changes along a nutrient gradient in Danish lakes. Ecol. Freshw. Fish, 15, 180-190.

Krebs C.J., 1989. Ecological Methodology, Harper and Row, New York, $654 \mathrm{p}$.

Kubečka J. and Prchalová M., 2006. Metodika odlovu a zpracování vzorků ryb stojatých vod, Výzkumný ústav vodohospodářský TGM, 22 p. (in Czech).

Lauridsen T.L., Søndergaard M., Jensen J.P. and Jeppesen E., 2005. Undersøgelser i søer - NOVANA. Danmarks Miljøundersøgelser, Teknisk anvisning fra DMU, 22, $234 \mathrm{p}$. (in Danish).

Lauridsen T.L., Landkildehus F., Jeppesen E., Jørgensen T.B. and Søndergaard M., 2008. A comparison of methods for calculating Catch Per Unit Effort (CPUE) of gill net catches in lakes. Fish. Res., 93, 204-211.

Mehner T., Diekmann M., Brämic U. and Lemcke R., 2005. Comparison of fish communities in German lakes as related to lake morphology, trophic state, shore structure and human use intensity. Freshw. Biol., 50, 70-85.

Mortensen E., Jerl Jensen H., Müller J.-P. and Timmermann M., 1990. Fiskeundersøgelser i søer - Undersøgelsesprogram, fiskeredskaber og metoder. Danmarks Miljøundersøgelser, 1990, Teknisk anvisning fra DMU, 3, 57 p. (in Danish).

Olin M. and Malinen T., 2003. Comparison of gillnet and trawl in diurnal fish community sampling. Hydrobiologia, 506-509, 443-449.

Olin M., Rask M., Ruuhijärvi J., Kurkilahti M., Ala-Opas P. and Ylönen O., 2002. Fish community structure in mesotrophic and eutrophic lakes of southern Finland: the relative abundance of percids and cyprinids along a trophic gradient. J. Fish Biol., 60, 593-612.

Olin M., Kurkilahti M., Peitola P. and Ruuhijärvi J., 2004. The effects of fish accumulation on the catchability of multimesh gillnet. Fish. Res., 68, 135-147.

Olin M., Malinen T. and Ruuhijärvi J., 2009. Gillnet catch in estimating the density and structure of fish community Comparison of gillnet and trawl samples in a eutrophic lake. Fish. Res., 96, 88-94.

Peltonen H., Ruuhijärvi J., Malinen T. and Horppila J., 1999. Estimation of roach (Rutilus rutilus (L.)) and smelt (Osmerus eperlanus (L.)) stocks with virtual population analysis, hydroacustics and gillnet CPUE. Fish. Res., 44, 25-36.

Prchalová M., Kubečka J., Říha M., Litvín R., Čech M., Frouzová J., Hladík M., Hohausová E., Peterka J. and Vašek M., 2008. Overestimation of percid fishes (Percidae) in gillnet sampling. Fish. Res., 91, 79-87.

Prchalová M., Kubečka J., Říha M., Mrkvička T., Vašek M., Jůza T., Kratochvíl M., Peterka J., Draštík V. and Křížek J., 2009. Size selectivity of standardized multimesh gillnets in sampling coarse European species. Fish. Res., 96, 51-57.

Rask M., Olin M., Keskitalo J., Lehtovaara A., Ruuhijärvi J. and Vesala S., 2003. Responses of plankton and fish communities to mass removal of planktivorous fish in a two-basin lake in southern Finland. Hydrobiologia, 506-509, 451-457.

Specziár A., 2001. Impacts of the activity of fish on the results of gillnet samplings: diurnal and seasonal changes of the CPUE in Lake Balaton. Hidrol. Közl., 81, 5/6, 459-461 (in Hungarian).

Specziár A., Tölg L. and Bíró P., 2000, Investigation of Lake Balaton's fish fauna. Halászatfejlesztés, 24, 115-125 (in Hungarian).

Sutela T., Rask M., Vehanen T. and Westermark A., 2008. Comparison of electrofishing and NORDIC gillnets for sampling littoral fish in boreal lakes. Lakes Reserv.: Res. Manage., 13, 215-220.

Tátrai I., Specziár A., György Á.I. and Bíró P., 2008. Comparison of fish size distribution and fish abundance estimates obtained with hydroacoustics and gill netting in the open water of a large shallow lake. Ann. Limnol. - Int. J. Lim., 44, 231-240.

Vašek M., Kubečka J., Čech M., Draštík V., Matěna J., Mrkvička T., Peterka J. and Prchalová M., 2009. Diel variation in gillnet catches and vertical distribution of pelagic fishes in a stratified European reservoir. Fish. Res., 96, 64-69. 